\title{
Katalogisasi Koleksi Perpustakaan Kecil Daerah Sindanglaya
}

\author{
Najlaa Syarif \\ Fakultas Ilmu Komunikasi, Universitas Padjadjaran \\ E-mail: najlaa20001@mail.unpad.ac.id \\ Evi Nursanti Rukmana \\ Fakultas Ilmu Komunikasi, Universitas Padjadjaran \\ E-mail: evi.nursanti.rukmana@unpad.ac.id \\ Asep Saeful Rohman \\ Fakultas Ilmu Komunikasi, Universitas Padjadjaran \\ E-mail: asep.saeful@unpad.ac.id
}

Received: 24-12-2021

Revised: 27-12-2021

Accepted: 30-12-2021

DOI: 10.24036/ib.v3i1.282

\begin{abstract}
Library services are an illustration of the fulfillment of library functions. One of the services that must be provided in the library is a catalog service. A service that makes it easier for users to find the collection they need in addition to asking a reference service. The catalog has three objects as mentioned by Cutter, namely the find function, the collect function, and the select function. In addition, the existence of a catalog can facilitate librarians in the collection development process. Therefore, a catalog should be in every library. The purpose of writing is to find out whether the use of catalogs in the intended library has been effective? Has the library implemented a catalog service? Is the SLiMS application in the Library effective to use? The author uses qualitative research methods so that the results obtained can be in accordance with the facts that appear and are seen when researchers observe the state of the object, namely the Sindanglaya Small Library. With the results of the study that the Sindanglaya Regional Small Library has not applied catalog services properly, only relying on the arrangement on the bookshelves so that researchers work with managers to use online catalogs by inputting data collections from the library using the SLiMS application.
\end{abstract}

Keywords: Cataloging, Collection, Library

\begin{abstract}
Abstrak
Layanan perpustakaan merupakan gambaran pemenuhan fungsi perpustakaan. Salah satu layanan yang harus disediakan di perpustakaan adalah layanan katalog. Sebuah layanan yang memudahkan pengguna untuk menemukan koleksi yang mereka butuhkan selain meminta layanan referensi. Katalog memiliki tiga objek seperti yang disebutkan oleh Cutter, yaitu fungsi find, fungsi collect, dan fungsi select. Selain itu, keberadaan katalog dapat memudahkan pustakawan dalam proses pengembangan koleksi. Oleh karena itu, katalog harus ada di setiap perpustakaan. Tujuan penulisan untuk mengetahui apakah penggunaan katalog pada perpustakaan yang dituju sudah efektif? Apakah perpustakaan sudah menerapkan layanan katalog? Apakah aplikasi SLiMS di Library efektif untuk digunakan? Penulis menggunakan metode penelitian kualitatif agar hasil yang diperoleh dapat sesuai dengan fakta yang muncul dan terlihat pada saat peneliti mengamati keadaan objek yaitu Perpustakaan Kecil Sindanglaya. Dengan hasil penelitian bahwa Perpustakaan Kecil Daerah Sindanglaya belum menerapkan layanan katalog dengan baik, hanya mengandalkan penataan pada rak buku sehingga peneliti bekerjasama dengan pengelola untuk
\end{abstract}


Published by Program Studi Perpustakaan dan IImu Informasi

FBS Universitas Negeri Padang, Indonesia

menggunakan katalog online dengan menginput data koleksi dari perpustakaan menggunakan aplikasi SLiMS.

Kata Kunci: Katalogisasi, Koleksi, Perpustakaan

\section{PENDAHULUAN}

Perpustakaan melalui Kamus

Besar Bahasa Indonesia yang dikutip oleh Yusuf (2016) dapat didefinisikan sebagai, "tempat, gedung, ruang yang disediakan untuk pemeliharaan dan penggunaan koleksi buku tersebut; koleksi buku, majalah, dan bahan kepustakaan lainnya yang disimpan untuk dibaca, dipelajari, dibicarakan". Melalui definisi tersebut, perpustakaan memiliki batasan bahwa perpustakaan hanya berupa tempat juga koleksi dan bahan informasi lainnya yang dihimpun, dipelihara, dan digunakan. Jika hal tersebut dipahami lebih dalam kita dapat mengartikan bahwa perpustakaan memiliki fungsi sebagai pemelihara, penyimpan, dan penyedia koleksi informasi yang dibutuhkan oleh siapapun. Dimana hal tersebut berkaitan pula dengan pelayanan dan fasilitas yang diberikan oleh perpustakaan itu sendiri kepada pengguna.
Ketika seorang pengguna memiliki niat untuk mendatangi perpustakaan, sudah dipastikan bahwa mereka sudah memiliki koleksi tertentu yang mereka butuhkan dan tugas perpustakaan adalah untuk mempertemukan pengguna tersebut dengan informasi yang dibutuhkannya. Terdapat berbagai cara untuk mempertemukan keduanya, selain dengan menyediakan layanan referensi, perpustakaan juga harus menyediakan katalog yang menghimpun dan menggelompokkan seluruh koleksi yang tersimpan di dalam perpustakaan tersebut. Merujuk pada pengertian Basuki (1991), katalog perpustakaan adalah daftar buku dalam sebuah perpustakaan atau dalam sebuah koleksi.

Tujuan dari katalog itu sendiri telah dipaparkan oleh Charles A. Cutter dalam karyanya, Rules for a Printed Dictionary Catalog pada tahun 1876. Mengutip melalui Joudrey \& Taylor (2018), Cutter memberikan tiga objek 
tujuan dari katalog, yaitu fungsi menemukan, fungsi mengumpulkan, dan fungsi menyeleksi. Dalam katalog online, pengguna dapat dengan mudah memasukan kata kunci ke dalam search engine dan dengan cepat akan memperlihatkan hasil yang berkaitan. Sehingga dapat disimpulkan bahwa katalog online lebih praktis dan efektif dibandingkan dengan kartu katalog yang dimana pengguna harus mencari satu-satu lokasi dari koleksi yang dibutuhkannya berdasarkan dengan daftar yang disajikan. Selain dengan mempertemukan pengguna dengan informasi yang dibutuhkan mereka, mengutip melalui Joudrey \& Taylor (2018) katalog juga membantu para pustakawan di perpustakaan tersebut yang perlu mengambil sumber informasi atau yang perlu mengambil informasi tentang seluruh sumber daya yang ada di perpustakaan (metadata) untuk bekerja dengan koleksi. Hal tersebut dapat membantu pustakawan dalam proses pengembangan koleksi yang akan dilakukan oleh pustakawan secara berkala.
Sesuai dengan penjelasan sebelumnya, eksistensi dari katalog itu sendiri adalah hal yang penting dalam sebuah perpustakaan, hal tersebut tentu harus memperhatikan pengguna dan teknologi yang ada dan yang terus berkembang. Sehingga pengguna juga dapat dengan mudah mencari dan menemukan apa yang dibutuhkan oleh mereka. Penulis dalam penelitian ini ingin mengetahui jika Perpustakaan Kecil Daerah Sindanglaya sudah memiliki layanan katalog yang akhirnya mempermudah pengunjung yang membutuhkan koleksi informasi yang dibutuhkan yang juga agar sejalan dengan tujuan dari adanya perpustakaan itu sendiri. Cutter, seperti yang dikutip oleh Deffenbaugh (2003), mengatakan bahwa "the convenience of the user must be put before the ease of the cataloger," dimana dalam ungkapan tersebut Cutter mengatakan bahwa, "kenyamanan pengguna harus didahulukan dari kemudahan pembuat katalog," sehingga seperti yang sudah diketahui, katalog dibuat untuk mempermudah dan meningkatkan kenyamanan para pengguna itu sendiri. 
Penulis yang sekaligus berperan sebagai peneliti akan terjun langsung dan mengobservasi Perpustakaan Kecil Daerah Sindangalaya dan sekaligus membantu pengelola untuk mengadai layanan katalogisasi menggunakan aplikasi SLiMS. Adapun tujuan penulis dalam pembuatan tulisan ini untuk mengetahui apakah penggunaan katalog di perpustakaan sudah efektif? Apakah perpustakaan sudah mengaplikasikan katalogisasi online? Apakah aplikasi SLiMS dalam Perpustakaan efektif digunakan? Dengan begitu, dapat diketahui jika Perpustakaan Kecil Daerah Sindanglaya telah memenuhi tujuan dan fungsi dari perpustakaan.

\section{METODE}

Proses pembuatan sebuah tulisan diperlukan metode penelitian agar penelitian yang dilakukan oleh penulis berjalan dengan sistematis sesuai dengan metode penelitian yang telah ditentukan. Metode penelitian dilakukan agar informasi dan data yang tersaji dalam tulisan yang dibuat diperkuat dengan informasi yang didukung dengan data tertulis maupun yang berasal dari sumber yang terpercaya. Dikutip melalui Sendrian dan Rahmi (2019), Sugiyono (2012) menuturkan bahwa, "metode penelitian adalah cara ilmiah untuk mendapatkan data dengan tujuan dan kegunaan tertentu". Dengan begitu, penulis harus menggunakan metode penelitian yang tepat agar data dan informasi yang dibutuhkan untuk mendukung penulisan tulisan dapat terpenuhi.

Metode dalam penulisan jurnal ini adalah metode penelitian kualitatif deskriptif. Dimana mengutip dari Lestari (2021) penelitian kualitatif adalah "salah satu jenis metode penelitian untuk mengungkapkan kejadian atau fakta, keadaan, fenomena, variabel dan keadaan yang terjadi saat penelitian berlangsung dengan menyuguhkan apa yang sebenarnya terjadi". Penulis memilih pendekatan kualitatif karena penulis menginginkan penelitian yang menyeluruh dan tidak terbatas terhadap hasil statistik. Dalam bukunya, Sugiyono (2013) menyebut metode kualitatif pun kerap kali disebut sebagai "metode pendekatan baru, postpositivistic, discovery, 
Published by Program Studi Perpustakaan dan IImu Informasi

interpretive, dan kualitatif". Menurut Sugiyono, "metode deskriptif kualitatif adalah metode penelitian yang berdasarkan pada filsafat postpositivisme yang sering juga disebut sebagai paradigma interpretif dan konstruktif, yang memandang realitas sosial sebagai sesuatu yang holistik/utuh, kompleks, dinamis, penuh makna, dan hubungan gejala bersifat interaktif (reciprocal). Metode kualitatif deskriptif digunakan untuk meneliti pada kondisi objek yang alamiah (sebagai lawannya adalah eksperimen) dimana dalam penelitiannya adalah human instrument atau peneliti itu sendiri yang sebagai instrumen.

Penelitian deskriptif kualitatif bertujuan untuk menggambarkan, melukiskan, menerangkan, menjelaskan, dan menjawab secara lebih rinci permasalahan yang akan diteliti dengan mempelajari semaksimal mungkin seorang individu, suatu kelompok atau suatu kejadian. Dalam penelitian kualitatif, manusia merupakan instrumen penelitian dan hasil penulisannya berupa kata-kata atau pernyataan yang sesuai dengan keadaan sebenarnya".

Nawawi (2005) dalam jurnalnya menjelaskan bahwa metode deskriptif pendekatan kualitatif adalah "menggambarkan atau melukiskan keadaan objek penelitian pada saat sekarang berdasarkan fakta-fakta yang tampak atau sebagaimana adanya". Menurut Bogdan dalam Sugiyono (2013), proses dari penelitian kualitatif itu sendiri bagaikan seseorang yang hendak pergi piknik. Dimana orang tersebut hanya mengetahui tempat tujuan tetapi belum mengetahui apa yang terjadi di tempat tersebut. Peneliti baru akan tahu setelah mereka mulai memasuki objek yang diteliti dengan cara mengobservasi apa saja fenomena yang terjadi di tempat itu. Berkaitan dengan hal tersebut, alasan penulis memutuskan untuk menggunakan metode penelitian deskriptif kualitatif karena penulis ingin menggambarkan/mendeskripsikan fenomena dan keadaan dari objek yang sedang diteliti oleh penulis dengan transparan, spesifik, dan mendalam. Dimana dengan human instrument, 
penulis selaku instrumen dan subjek yang memasuki objek harus memiliki pengetahuan mengenai objek yang akan diteliti dan penelitian ini akan menyajikan gambaran keadaan sehingga data yang akan terkumpul bersifat deskriptif.

Penelitian ini dilakukan di Kota Bandung terhitung mulai dari 15 November 2021 hingga 6 Desember 2021. Penelitian ini dilaksanakan di Perpustakaan Kecil Daerah Sindanglaya yang merupakan perpustakaan dengan jumlah koleksi yang terhitung banyak namun masih terlihat belum dikelola dalam katalogisasi koleksinya. Dengan subjek maupun objek dari penelitian ini adalah pengelola dan pemustaka yang kerap datang ke perpustakaan sehingga informasi yang didapatkan dapat dipercaya dan sesuai dengan keadaan yang ada di Perpustakaan Kecil Daerah Sindanglaya. Adapun pihak-pihak tersebut antara lain:

1. Merry Ratna, pengelola Perpustakaan Kecil Daerah Sindanglaya 2. Salma Luthfiyyah, pemustaka Perpustakaan Kecil Daerah Sidanglaya
3. Dena Sutan, pemustaka Perpustakaan Kecil Daerah Sindanglaya Dengan objek penelitian dalam penelitian ini adalah koleksi dan penggunaan jenis katalog pada Perpustakaan Kecil Daerah Sindanglaya. Dalam penelitian yang dilakukan dan seperti yang sudah dibahas sebelumnya, diperlukan instrumen agar data dapat dihimpun dimana dalam penelitian ini, peneliti adalah instrumen aktif (human instrument) yang mengumpulkan data di tempat. Hal tersebut sejalan dengan pengertian dari penelitian kualitatif deskriptif itu sendiri dimana dalam pemilihan pendekatan kualitatif, peneliti adalah instrumen yang merencanakan, melaksanakan, mengumpulkan data, menganalisis, dan menafsirkan data.

Peneliti terjun langsung ke lapangan untuk mengobservasi fenomena dan keadaan yang ada di Perpustakaan Kecil Daerah Sindanglaya. Dimana dalam prosesnya, selain manusia, instrumen pengumpulan data lainnya adalah koleksi dan dokumen yang dapat 
Published by Program Studi Perpustakaan dan IImu Informasi FBS Universitas Negeri Padang, Indonesia

digunakan untuk mendukung

keabsahan hasil penelitian juga sebagai instrumen pendukung.

Dalam pengumpulan data, penulis melakukan wawancara kepada informan, melakukan observasi lingkungan, dan dokumentasi. Banister dkk dalam Poerwandari (1998) menuturkan bahwa wawancara dilakukan "bertujuan untuk memperoleh pengetahuan tentang makna-makna subjektif yang dipahami oleh individu berkenaan dengan topik yang diteliti”. Dengan hasil wawancara yang telah didapatkan, penulis akan menyajikan data dengan menggunakan kalimat langsung agar informasi data yang diberikan oleh informan dapat tersampaikan tanpa perbedaan maksud juga dengan kalimat deskriptif untuk ujaran informan yang sekiranya perlu diberikan perbaikan agar informasi lebih dimengerti oleh pembaca.

Dalam proses obsevasi, peneliti melakukan observasi langsung untuk mengamati fenomena yang terjadi dan memahami keadaan yang ada pada Perpustakaan Kecil Daerah Sindanglaya. Sedangkan untuk dokumentasi, disini peneliti mengumpulkan dan meninjau dokumen maupun koleksi yang tersedia untuk mendukung kelengkapan informasi yang didapat dalam proses wawancara dan observasi. Setelah mengumpulkan data, peneliti selanjutnya menganalisis data. Dimana analisis data adalah "proses mencari dan menyusun secara sistematis data yang diperoleh dari hasil wawancara, catatan lapangan, dan bahan-bahan lain, sehingga dapat mudah dipahami, dan temuannya dapat diinformasikan kepada orang lain" (Sugiyono, 2013). Dalam penelitian kualitatif, teknik analisis data dapat menggunakan teori analisis data oleh Miles dan Huberman (1984) dalam Sugiyono (2013), yaitu data reduction, data display, dan conclusion drawing/verification.

\section{HASIL DAN PEMBAHASAN}

Merujuk pada pengertian Basuki (1991), katalog perpustakaan adalah daftar buku dalam sebuah perpustakaan atau dalam sebuah koleksi. Dilanjutkan oleh Joudrey \& Taylor (2018), katalog menyediakan 
akses ke item individual dalam koleksi sumber informasi (misalnya, entitas fisik seperti buku, DVD, dan peta di perpustakaan; karya seniman di museum seni; halaman web). Setiap sumber diwakili oleh deskripsi yang agak lebih panjang dari entri dalam bibliografi. Deskripsi diberikan satu atau lebih titik akses. Deskripsi dalam katalog dibangun menurut gaya standar yang dipilih oleh komunitas tertentu yang salah satunya adalah International Standard Bibliographic Description (ISBD). Merujuk pada peraturan/standar deskripsi dari International Standard Bibliographic Description (ISBD), dalam sebuah katalog, harus terdapat delapan daerah deskripsi bibliografi yang meliputi: (1) Daerah judul dan pernyataan tanggungjawab; (2) Daerah edisi; (3) Daerah data khusus; (4) Daerah publikasi, produksi, distribusi, dsb; (5) Daerah deskripsi fisik; (6) Daerah seri; (7) Daerah catatan; dan (8) Daerah nomor standar.

Tujuan dari katalog itu sendiri telah dipaparkan oleh Charles A. Cutter dalam karyanya, Rules for a Printed
Dictionary Catalog pada tahun 1876. Mengutip melalui Joudrey \& Taylor (2018), Cutter memberikan tiga objek tujuan dari katalog, yang dapat disimpulkan menjadi fungsi menemukan dimana katalog harus membantu pengguna mengambil sumber daya jika salah satu titik akses kuncinya diketahui dan itu adalah bagian dari koleksi, fungsi mengumpulkan dimana katalog harus dapat menampilkan semua sumber daya dalam koleksi oleh pencipta, pada subjek tertentu, atau dalam genre atau bentuk sastra tertentu, dan fungsi menyeleksi dimana untuk membantu pengguna memilih sumber daya yang mereka butuhkan berdasarkan atribut bibliografi atau sifat konten. Namun, Basuki (1991) membahas lebih lanjut objek perpustakaan Cutter tersebut, dimana “(1) memungkinkan seseorang menemukan sebuah buku yag diketahui berdasarkan, (a) pengarangnya, (b) judulnya, (c) subjeknya. Dalam tujuan pertama ini menekankan bahwa katalog perpustakaan bertindak sebagai daftar temuan bagi dokumen tertentu; (2) menunjukkan buku yang 
dimiliki perpustakaan, (a) oleh pengarang tertentu, (b) berdasarkan subjek tertentu, (c) dalam jenis literatur tertentu. Menekankan bahwa katalog perpustakaan harus bertindak sebagai daftar temuan bagi sekelompok dokumen; (3) membantu dalam pemilihan buku, (a) berdasarkan edisinya (b) berdasarkan karakternya (sastra atau topik). Objek ketiga ini berkaitan dengan deskripsi buku dalam katalog, sehingga pengguna dapat membedakan berbagai edisi”.

Dengan penjelasan dari objekobjek katalog perpustakaan, diharapkan dengan adanya katalog tersebut dapat memudahkan proses pertemuan antar pengguna dengan informasi yang dibutuhkan mereka atau temu balik informasi yang mana adalah fungsi dari perpustakaan itu sendiri. Selain itu, mengutip dari Joudrey \& Taylor (2018) katalog juga membantu para pustakawan di perpustakaan tersebut yang perlu mengambil sumber informasi atau yang perlu mengambil informasi tentang seluruh sumber daya yang ada di perpustakaan (metadata) untuk bekerja dengan koleksi. Tujuan penting ini adalah pelayanan oleh katalog secara tradisional yang bertindak sebagai inventaris koleksi. Katalog yang disusun dalam urutan di mana sumber informasi, objek, dan sebagainya, diatur di rak. Hal tersebut dapat membantu pustakawan dalam proses pengembangan koleksi yang akan dilakukan oleh perpustakaan secara berkala sehingga dapat mengetahui koleksi apa saja yang sudah ada dan yang perlu diadakan agar kebutuhan pengguna dapat pula terpenuhi.

Katalog memiliki jenis yang beragam seiring dengan perkembangan teknologi dan penggunaannya. Katalog buku adalah jenis katalog yang digunakan pertama kali dalam penemuannya. Joudrey \& Taylor (2018) dalam bukunya menjelaskan bahwa katalog buku hanyalah sebuah daftar tulisan tangan yang selanjutnya dicetak tapi tidak selalu dalam urutan yang terlihat. Katalog buku sangat mahal untuk diproduksi sehingga akan lama untuk memperbarui katalog. Namun, katalog buku masih ada di beberapa perpustakaan dan arsip sebagai satu- 
satunya alat temu kembali yang tersedia untuk mengakses materi lama, karena beberapa institusi telah memilih untuk tidak mengubah semua catatan katalog untuk koleksi yang jarang digunakan menjadi bentuk yang dapat dibaca mesin untuk katalog online. Katalog buku pun kompak dan mudah untuk dibawa-bawa.

Sedangkan katalog kartu dibuat menggunakan tulisan tangan yang akhirnya digunakan lah mesin ketik yang membuat katalog kartu dapat diperbarui segera setelah kartu dapat diajukan dan relatif murah untuk dipelihara dan dibuat. Seiring dengan perkembangan teknologi, katalog online pun menggantikan katalog buku dan kartu di sebagian besar negara yang berteknologi maju dan diuntungkan secara ekonomi. Dalam katalog online, pengguna dapat dengan mudah memasukan kata kunci ke dalam search engine dan dengan cepat akan memperlihatkan hasil yang berkaitan. Sehingga dapat disimpulkan bahwa katalog online lebih praktis dan efektif dibandingkan dengan kartu katalog yang dimana pengguna harus mencari satu-satu lokasi dari koleksi yang dibutuhkannya berdasarkan dengan daftar yang disajikan.

Pada Perpustakaan Kecil Daerah Sindanglaya, peneliti menemukan bahwa pustakwan dari perpustakaan tersebut masih belum menggunakan jenis katalog apapun. Sehingga pengguna yang mengunjungi perpustakaan harus mencari sendiri koleksi informasi yang mereka butuhkan dengan melihat rak-rak buku satu-persatu. Fenomena tersebut membuat Perpustakaan Kecil Daerah Sindanglaya dinyatakan belum memenuhi fungsi perpustakaan yang seharusnya. Keadaan bahwa perpustakaan tersebut yang kecil dan tidak mendapati dana dari pihak manapun, yang hanya mengandalkan sumbangan koleksi dari masyarakat sekitar mendukung alasan mengapa perpustakaan tersebut belum mengembangkan katalogisasi. Dengan begitu, peneliti dengan tujuan yang ada pun membantu pustakawan dan pengelola Perpustakaan Kecil Daerah Sindanglaya untuk menggunakan SLiMS sebagai alat katalogisasi pada 
perpustakaan. Dimana pengguna akhirnya dapat mengakses daftar katalog melalui perangkat elektronik yang tersedia di perpustakaan yang disediakan dengan kesepakatan pengelola maupun pustakawan yang ada di perpustakaan. Dengan menggunakan SLiMS, pengguna koleksi dapat melihat koleksi yang tersedia di Perpustakaan Kecil Daerah Sindanglaya hanya dengan mengarungi daftar katalog yang terdapat di layar. Pengguna pun dapat mencari koleksi dengan menyebutkan subjek dari koleksi yang dibutuhkan. Pustakawan pun dapat dengan mudah meninjau kembali koleksi yang belum tersedia di perpustakaan.

Katalog online dikenal beragam, penulis dalam hal ini ingin mengaplikasikan penggunaan aplikasi SLiMS untuk membuat daftar katalog di Perpustakaan Kecil Daerah Sindanglaya. Aplikasi Senayan Library Management System (SLiMS) merupakan salah satu sistem automasi perpustakaan yang bersifat open source atau gratis. SLiMS merupakan peraih INAICTA (Indonesia Information
Communication and Technology Award) 2009 untuk kategori open soource (Ermawelis, 2018). SLiMS dikembangkan dan disempurnakan secara terus menerus, saat ini perkembangannya telah sampai ke versi 8.2 (akasia). SLiMS merupakan sistem automasi perpustakaan berbasis web dan dibangun menggunakan bahasa pemrograman PHP serta menggunakan MySQL sebagai basis data dan Apache sebagai web servernya.

\section{PENUTUP}

\section{Simpulan}

Berdasarkan pengamatan peneliti yang terjun langsung ke lapangan dan mengunjungi Perpustakaan Kecil Daerah Sindanglaya, penggunaan katalog di perpustakaan tersebut masih belum digunakan. Bahkan, pengelola dan pustakawan hanya mengandalkan penyusunan dan penempatan koleksi di rak-rak sesuai dengan subjek yang ada sehingga pengguna yang ingin menelusuri atau mencari koleksi yang dibutuhkan harus mencari satu-persatu 
koleksi yang dibutuhkan dengan menyusuri rak-rak perpustakaan. . Keadaan bahwa perpustakaan tersebut yang kecil dan tidak mendapati dana dari pihak manapun, yang hanya mengandalkan sumbangan koleksi dari masyarakat sekitar mendukung alasan mengapa perpustakaan tersebut belum mengembangkan katalogisasi. Dengan adanya perangkat elektronik yang dapat digunakan akhirnya peneliti bekerja bersama dengan pengelola maupun dengan pustakawan untuk meng-input data koleksi yang dimiliki oleh Perpustakaan Kecil Daerah Sindanglaya sehingga fungsi daru perpustakaan dapat terpenuhi. Daftar katalog dimasukan ke dalam aplikasi Senayan Library Management System (SLiMS) dimana dalam aplikasi tersebut, deskripsi bibliografis yang menjadi unsur-unsur katalog tersedia dan tidak mengabaikan delapan daerah deskripsi bibliografis tersebut.

\section{DAFTAR PUSTAKA}

Basuki, Sulistyo. 1991. Pengantar Ilmu Perpustakaan. Jakarta: Gramedia. Buckland, Michael K. 1991.
"Information as Thing." Journal of the American Society for Information Science 42(5):35160. doi: 10.1002/(SICI)10974571(199106)42:5<351::AIDASI5>3.0.CO;2-3.

Chu, Felix T. 2007. "Bridging the LISPractitioner Gap: Some Frames for Research." Library Philosophy and Practice 2007(JUNE).

Deffenbaugh, James T. 2003. Metadata Fundamentals for All Librarians. Vol. 29.

Ermawelis, Ermawelis. 2018.

“Teknologi Informasi Untuk Perpustakaan, Pusat Dokumentasi Dan Informasi." AL MUNIR : Jurnal Komunikasi Dan Penyiaran Islam (1):11-18. doi: 10.15548/amjkpi.v0i1.5.

Gultom, Hetty. 2014. “Analisis Subjek Bahan Pustaka." 13.

IFLA. 2011. "ISBD: International Standard Bibliographic Description." ISBD: International Standard Bibliographic Description. doi: 
10.1515/9783598440359.

Joudrey, Daniel N., and Arlene G. Taylor.

2018. The Organization of

Information. 4th ed. California:

Libraries Unlimited.

Lestari, Annisa Dwi, Sukaesih, Evi

Nursanti Rukmana, and Asep

Saeful Rohman. 2021.

“Perpustakaan Digital Sebagai

Alternatif Utama Dalam

Memberikan Layanan Pada Masa

Pandemi Di Dinas Arsip Dan

Perpustakaan Kabupaten

Bandung." Al-Khuttah: Jurnal

Kajian Perpustakaan, Informasi,

Dan Kearsipan 3(1):22-32.

Nawawi, Hadari. 2005. "Penelitian

Terapan." Gajah Mada University

Press.

Poerwandari, Elizabeth Kristi. 1998.

"Pendekatan Kualitatif Untuk

Penelitian Perilaku Manusia."

LPSP3 Fakultas Psikologi
Universitas Indonesia 2.

Sendrian, R., dan Rahmi, Lailatur. 2019.

“Pergeseran Layanan

Perpustakaan Perguruan Tinggi

Melalui Konsep Virtual Library."

Shaut Al-Maktabah Jurnal

Perpustakaan, Arsip, Dan

Informasi 11(1):52-65. doi:

10.15548/shaut.v11i1.127.

Subrata, Gatot. 2009. "Tajuk Subyek.”

Pustakawan Peprustakaan UM 1-

11.

Sugiyono, Prof. Dr. 2013. Metode

Penelitian Kuantitatif Kualitatif

Dan $R \& D$. Bandung: Penerbit

Alfabeta Bandung.

Suharyanto. 2014. "Pengeloaan E-

Resources Dengan AACR2 Dan

MARC 21.” Visi Pustaka 16.

Yusuf, Pawit M. 2016. Ilmu Informasi,

Komunikasi, Dan Kepustakaan.

2nd ed. Jakarta: Bumi Aksara. 